\title{
Article
}

\section{Tafel Slope Analyses for Homogeneous Catalytic Reactions}

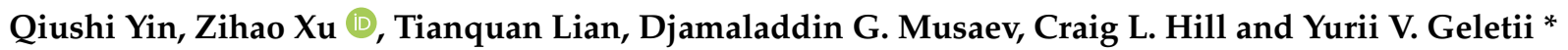

Department of Chemistry, Emory University, Atlanta, GA 30322, USA; benjamin.yin@emory.edu (Q.Y.); zihao.xu@emory.edu (Z.X.); tlian@emory.edu (T.L.); dmusaev@emory.edu (D.G.M.); chill@emory.edu (C.L.H.)

* Correspondence: Iguelet@emory.edu

check for

updates

Citation: Yin, Q.; Xu, Z.; Lian, T.;

Musaev, D.G.; Hill, C.L.; Geletii, Y.V.

Tafel Slope Analyses for

Homogeneous Catalytic Reactions.

Catalysts 2021, 11, 87. https://

doi.org/10.3390/catal11010087

Received: 25 December 2020

Accepted: 8 January 2021

Published: 11 January 2021

Publisher's Note: MDPI stays neutral with regard to jurisdictional clai$\mathrm{ms}$ in published maps and institutional affiliations.

Copyright: $\odot 2021$ by the authors. Licensee MDPI, Basel, Switzerland. This article is an open access article distributed under the terms and conditions of the Creative Commons Attribution (CC BY) license (https:// creativecommons.org/licenses/by/ $4.0 /)$.

\begin{abstract}
Tafel analysis of electrocatalysts is essential in their characterization. This paper analyzes the application of Tafel-like analysis to the four-electron nonelectrochemical oxidation of water by the stoichiometric homogeneous 1-electron oxidant $\left[\mathrm{Ru}(\mathrm{bpy})_{3}\right]^{3+}$ to dioxygen catalyzed by homogeneous catalysts, $\left[\mathrm{Ru}_{4} \mathrm{O}_{4}(\mathrm{OH})_{2}\left(\mathrm{H}_{2} \mathrm{O}\right)_{4}\left(\gamma-\mathrm{SiW}_{10} \mathrm{O}_{36}\right)_{2}\right]^{10-}\left(\mathbf{R u}_{4} \mathbf{P O M}\right)$ and $\left[\mathrm{Co}_{4}\left(\mathrm{H}_{2} \mathrm{O}\right)_{2}\left(\mathrm{PW}_{9} \mathrm{O}_{34}\right)_{2}\right]^{10-}$ $\left(\mathrm{Co}_{4} \mathrm{POM}\right)$. These complexes have slow electron exchange rates with electrodes due to the Frumkin effect, which precludes the use of known electrochemical methods to obtain Tafel plots at ionic strengths lower than $0.5 \mathrm{M}$. The application of an electron transfer catalyst, $\left[\mathrm{Ru}(\mathrm{bpy})_{3}\right]^{3+/ 2+}$, increases the rates between the $\mathbf{R u _ { 4 }}$ POM and electrode, but a traditional Tafel analysis of such a complex system is precluded due to a lack of appropriate theoretical models for 4-electron processes. Here, we develop a theoretical framework and experimental procedures for a Tafel-like analysis of $\mathbf{R} \mathbf{u}_{4} \mathbf{P O M}$ and $\mathbf{C o}_{4} \mathbf{P O M}$, using a stoichiometric molecular oxidant $\left[\mathrm{Ru}(\mathrm{bpy})_{3}\right]^{3+}$. The dependence of turnover frequency (TOF) as a function of electrochemical solution potential created by the $\left[\mathrm{Ru}(\mathrm{bpy})_{3}\right]^{3+} /\left[\mathrm{Ru}(\mathrm{bpy})_{3}\right]^{2+}$ redox couple (an analog of the Tafel plot) was obtained from kinetics data and interpreted based on the suggested reaction mechanism.
\end{abstract}

Keywords: Tafel; polyoxometalate; water oxidation; stopped-flow; kinetics; catalyst comparison

\section{Introduction}

Tafel slope analysis has become increasingly popular in this era of solar fuels research and photoelectrochemistry [1-6]. This study addresses the possibility of constructing Tafel plots for homogeneous catalytic multielectron redox processes and the usefulness of this approach. The model homogeneous reaction we have chosen for this study is the oxidation of water in Equation (1).

$$
\begin{gathered}
2 \mathrm{H}_{2} \mathrm{O}-4 \mathrm{e}^{-} \rightarrow \mathrm{O}_{2}+4 \mathrm{H}^{+} \\
2 \mathrm{H}^{+}+2 \mathrm{e}^{-} \rightarrow \mathrm{H}_{2} \\
2 \mathrm{H}_{2} \mathrm{O} \rightarrow \mathrm{O}_{2}+2 \mathrm{H}_{2}
\end{gathered}
$$

Equation (1) is very unfavorable thermodynamically and requires an external source of energy such as electricity or light (e.g., solar). The overall reaction of water splitting, Equation (3), includes two half-reactions, water oxidation and reduction, Equations (1) and (2), respectively, which proceed in spatially separated sites:

The reverse reaction in Equation (3) takes place in fuel cells to directly convert chemical energy into electricity.

In electrochemistry, the potential applied between the cathode and anode and the current is measured. Commonly, the empirically formulated Tafel relation in Equation (4) is used to compare the electrocatalytic activities:

$$
\eta=a+b \log (i)
$$

where $\eta=E-E_{0}$ is the difference between the electrode and standard potentials, $i$ is the current density, and $\mathrm{b}$ is the Tafel slope. 
The utility of Tafel slopes from a microkinetic analysis of aqueous electrocatalysis for energy conversion has been reported [1,2]. However, numerous simplifications and assumptions in the derivation of Equation (4) leads to an incomplete description of the actual surface kinetics and makes the applicability of Tafel analysis questionable $[2,3,7,8]$. In many cases, homogeneous systems are simpler and easier experimentally for understanding the reaction mechanism. Therefore, we developed a protocol to construct Tafel-like plots for homogeneous reactions and studied the usefulness of such plots to better understand the reaction mechanism. In addition, while extensive mechanistic analyses of molecular redox systems have been conducted previously, many aspects still need to be precisely addressed [9]. Generally speaking, the Tafel-like plot is one among multiple approaches that link the kinetic and thermodynamic properties of such a catalytic system.

Both half reactions, Equations (1) and (2), are complex multielectron processes catalyzed by transition metal complexes. Each one is routinely studied individually $[6,10-12]$. Stable homogeneous molecular catalysts are ideally suited for studies of the reaction mechanism and the relationship between reaction kinetics and thermodynamics. Indeed, previous studies on redox and chemical catalysts in different catalytic systems have already provided theoretical tools for mechanistic analyses [9]. More recently, Costentin and Savéant thoroughly analyzed the applicability of the Tafel equation to the homogeneous molecular catalysis of electrochemical $\mathrm{CO}_{2}$ and $\mathrm{O}_{2}$ reduction [13]. In this work, we describe a protocol for deriving a Tafel-like plot based on theoretical and experimental grounds to relate the reaction rate with the solution electrochemical potential for homogeneous water oxidation by $\left[\mathrm{Ru}(\mathrm{bpy})_{3}\right]^{3+}$, catalyzed by the stable molecular tetraruthenium polyoxometalate $\left[\mathrm{Ru}_{4} \mathrm{O}_{4}(\mathrm{OH})_{2}\left(\mathrm{H}_{2} \mathrm{O}\right)_{4}\left(\gamma-\mathrm{SiW}_{10} \mathrm{O}_{36}\right)_{2}\right]^{10-}, \mathbf{R u}_{4} \mathbf{P O M}$. This POM was the first fully inorganic (carbon-free), thus oxidatively robust, water oxidation catalyst (WOC), which is also hydrolytically stable over a wide $\mathrm{pH}$ range (pH 1-9) [14,15]. Detailed electrochemical studies of this complex showed that the rates of electron exchange between an electrode and the complex is sluggish under typical catalytic turnover conditions [14,16]. As a result, neither the Tafel plot nor the exchange current density, $i_{0}$, can be measured experimentally. At the same time, the catalyst shows excellent activity in homogeneous aqueous solutions when stoichiometric oxidants such as $\mathrm{Ce}(\mathrm{IV})$ or $\left[\mathrm{Ru}(\mathrm{bpy})_{3}\right]^{3+}$ are used. The question was posed as to whether data collected in homogeneous multielectron processes can be used to obtain a Tafel-like plot. This study addresses that question and aims to focus on the adaptation of an analog of traditional Tafel plots to the four-electron water oxidation process specific to homogeneous species.

\section{Results and Discussion}

\subsection{Theoretical Considerations}

Here, we assume that water oxidation in homogeneous conditions proceeds through four fast Nernstian reversible electron transfer steps followed by the irreversible $\mathrm{O}_{2}$ formation step, Equations (5-8), where $\mathrm{C} 0$ is the resting oxidation state of the catalyst, $\mathrm{C}$, and $\mathrm{C} 1-\mathrm{C} 4$ are the one- to four-electron oxidized forms of the catalyst.

$$
\begin{aligned}
& \mathrm{C} 0-\mathrm{e} \rightleftarrows \mathrm{C} 1 \quad \mathrm{E}_{1}^{\mathrm{o}} \\
& \mathrm{C} 1-\mathrm{e} \rightleftarrows \mathrm{C} 2 \quad \mathrm{E}^{\mathrm{o}}{ }_{2} \\
& \mathrm{C} 2-\mathrm{e} \rightleftarrows \mathrm{C} 3 \quad \mathrm{E}^{\mathrm{o}}{ }_{3} \\
& \mathrm{C} 3-\mathrm{e} \rightleftarrows \mathrm{C} 4 \quad \mathrm{E}^{\mathrm{o}}{ }_{4} \\
& \mathrm{C} 4+2 \mathrm{H}_{2} \mathrm{O} \rightarrow \mathrm{C} 0+\mathrm{O}_{2}+4 \mathrm{H}^{+} \quad \mathrm{k}_{\mathrm{o}}
\end{aligned}
$$

If the equilibria are fast, then an applied and electrochemical solution potential, E, is linked via the Nernst equation, Equation (10):

$$
\begin{aligned}
& \mathrm{E}-\mathrm{E}^{\mathrm{o}}{ }_{1}=(\mathrm{RT} / \mathrm{F}) \times \ln ([\mathrm{C} 1] /[\mathrm{C} 0]), \mathrm{E}-\mathrm{E}^{\mathrm{o}}{ }_{2}=(\mathrm{RT} / \mathrm{F}) \times \ln ([\mathrm{C} 2] /[\mathrm{C} 1]), \mathrm{E}-\mathrm{E}^{\mathrm{o}}{ }_{3}=(\mathrm{RT} / \mathrm{F}) \times \ln ([\mathrm{C} 3] /[\mathrm{C} 2]), \\
& \mathrm{E}-\mathrm{E}^{\mathrm{o}}{ }_{4}=(\mathrm{RT} / \mathrm{F}) \times \ln ([\mathrm{C} 4] /[\mathrm{C} 3]),
\end{aligned}
$$


where $\mathrm{R}$ is the universal gas constant, $\mathrm{T}$ is the temperature, and $\mathrm{F}$ is the Faraday constant. The concentration of the catalyst in oxidation state $i=0-4$ is described by a distribution function, Equation (11):

$$
\begin{gathered}
\alpha_{\mathrm{i}}=[\mathrm{Ci}] /[\mathrm{Ct}] \times\left[\exp \left(\mathrm{F}\left(\mathrm{iE}-\sum_{0}^{\mathrm{i}} \mathrm{E}_{\mathrm{i}}^{\mathrm{o}}\right) / \mathrm{RT}\right)\right] /\left[1+\exp \left[\mathrm{F}\left(\mathrm{E}-\sum_{0}^{1} \mathrm{E}_{\mathrm{j}}^{\mathrm{o}}\right) / \mathrm{RT}\right]+\exp \left[\mathrm{F}\left(2 \mathrm{E}-\sum_{0}^{2} \mathrm{E}_{\mathrm{j}}^{\mathrm{o}}\right) \mathrm{RT}\right]\right. \\
+\exp \left[\mathrm{F}\left(3 \mathrm{E}-\sum_{0}^{3} \mathrm{E}_{\mathrm{j}}^{\mathrm{o}}\right) / \mathrm{RT}\right]+\exp \left[\left(4 \mathrm{E}-\sum_{0}^{4} \mathrm{E}_{\mathrm{j}}^{\mathrm{o}}\right) / \mathrm{RT}\right]
\end{gathered}
$$

where $[\mathrm{Ct}]=$ total concentration of the catalyst.

If a stoichiometric oxidant is used as a sacrificial electron acceptor, the Nernst law gives the applied potential equal to the solution potential. Here, we consider the case when $\left[\mathrm{Ru}(\mathrm{bpy})_{3}\right]^{3+}, \mathrm{Ru} 3$, is an oxidant $\left(\mathrm{Ru} 2\right.$ represents $\left.\left[\mathrm{Ru}(\mathrm{bpy})_{3}\right]^{2+}\right)$. The electrochemical solution potential, $\mathrm{E}$, created by this oxidant is:

$$
\begin{gathered}
\mathrm{E}=\mathrm{E}_{0}^{\prime}+0.059 \times \log _{10}([\mathrm{Ru} 3] /[\mathrm{Ru} 2])=\mathrm{E}_{0}^{\prime}+0.059 \times \log _{10}([\mathrm{Ru} 3] /([\mathrm{Ru} 3] \mathrm{o}- \\
[\mathrm{Ru} 2]+[\mathrm{Ru} 2] \mathrm{o})),
\end{gathered}
$$

where $\mathrm{E}_{0}^{\prime}=1.26 \mathrm{~V}$ (SHE) is the standard reduction potential of the Ru3/Ru2 couple, and [Ru3]o and [Ru2]o are the initial concentrations of Ru3 and Ru2, respectively.

If the rate limiting step is Equation (9), then the reaction rate (current) is:

$$
-\mathrm{d}[\mathrm{Ru} 3] / \mathrm{dt}=4 \mathrm{k}_{\mathrm{o}}[\mathrm{C} 4]=\mathrm{TOF}_{\mathrm{app}} \times[\mathrm{Ct}]
$$

and the apparent turnover frequency ( $\left.\mathrm{TOF}_{\mathrm{app}}\right)$ with respect to Ru3 consumption is:

$$
\mathrm{TOF}_{\mathrm{app}}=4 \alpha_{4} \mathrm{k}_{\mathrm{o}}
$$

Here, $\mathrm{k}_{\mathrm{o}}$ is the rate constant for the oxidation of water. The value of the distribution factor, $\alpha_{4}$ is time-dependent and can be determined from Equations (10) and (11), and TOF app is a kinetic parameter. The full equation linking $\mathrm{TOF}_{\mathrm{app}}$ and apparent potential is complex, but can be simplified if $\mathrm{k}_{\mathrm{o}}$ is known and [Ru2]o $=0$, Equation (15):

$$
\log _{10}\left(\mathrm{TOF}_{\mathrm{app}}\right) \approx \log _{10}\left(4 \mathrm{k}_{\mathrm{o}}\right)+\mathrm{E}_{0}^{\prime}+0.059 \times \log _{10}([\mathrm{Ru} 3] /([\mathrm{Ru} 3] \mathrm{o}-[\mathrm{Ru} 3]))-4 \mathrm{E}
$$

At high applied potentials, $[C 4] \approx[C t]$ and $\mathrm{TOF}_{\text {app }}$ reaches a plateau with the value $4 \mathrm{k}_{\mathrm{o}}$. This value is the maximum turnover frequency (TOF) achievable by a given catalyst. This is an intrinsic property of a catalyst and its associated turnover activity. However, $\mathrm{TOF}_{0}$ of a certain catalytic system can be achieved at different potentials, $\mathrm{E}_{\mathrm{TOF}}$. As a result, the catalytic activity of two systems cannot be compared by a single number such as $\mathrm{TOF}_{0}$. Two parameters, $\mathrm{TOF}_{0}$ and $\mathrm{E}_{\mathrm{TOF}}$, are required to describe the catalytic activity. The slope of the Tafel-like plot at moderate potentials is a complex dependence of the catalyst reduction potentials and the Ru3 concentration. In our homogeneous catalytic system, Ru3 is used as a stoichiometric electron acceptor. Ru3 can also be generated in situ in a photoinduced reaction of Ru2 with persulfate, $\mathrm{S}_{2} \mathrm{O}_{8}{ }^{2-}$, or electrochemically.

\subsection{Homogeneous Electrochemical Reactions in the Presense of an Electron Transfer Catalyst}

As the electron transfer from Ru4POM to the electrode is slow, we attempted to accelerate the overall reaction with the addition of an electron transfer catalyst.

The stability of Ru3 is well documented to increase at lower $\mathrm{pH}$. Therefore, the cyclic voltammetry (CV) was recorded at a slightly lower $\mathrm{pH}$ of 7.2. The CV of Ru3/Ru2 has an almost ideal shape with an anodic-cathodic peak separation of $69 \mathrm{mV}$ and a ratio of anodic and cathodic current close to $1 ; \mathrm{E}_{1 / 2}=1.26 \mathrm{~V}$ (versus SHE) in $80 \mathrm{mM}$ sodium phosphate buffer at $\mathrm{pH}$ 7.2. The addition of $15 \mu \mathrm{M}$ of $\mathbf{R} \mathbf{u}_{4} \mathbf{P O M}$ to $1.0 \mathrm{mM}$ Ru2 results in a slight increase in anodic current (Figure 1), indicating that the reaction between Ru3 and $\mathbf{R u}_{4} \mathbf{P O M}$ takes place. At higher concentration, $\mathbf{R} \mathbf{u}_{4} \mathbf{P O M}$ forms an insoluble adduct with Ru2, which does not allow CV measurements over a broad range of catalyst concentrations. A foot of the wave analysis cannot be applied, as no catalytic current is 
seen in this system [17]. The CV simulation with the SIM4YOU software package using the heterogeneous electron transfer reaction rate constant $0.065 \mathrm{~cm} \mathrm{~s}^{-1}$ (measured in $0.1 \mathrm{M}$ $\mathrm{H}_{2} \mathrm{SO}_{4}$ ) [18] for Ru3 and a glassy carbon electrode (surface area is $0.0668 \mathrm{~cm}^{2}$ ) is in good agreement with the experiment under the assumption of irreversible oxidation of Ru3 at the electrode at a potential of $1840 \mathrm{mV}$ vs. SHE (Figure 1). The simulation results in the presence of $\mathbf{R} \mathbf{u}_{4} \mathbf{P O M}$ is also in reasonable agreement with the experiment when the reaction mechanism and rate constants described below are applied. Clearly, simple cyclic voltammograms do not provide much information on $\mathbf{R} \mathbf{u}_{4}$ POM redox potentials.

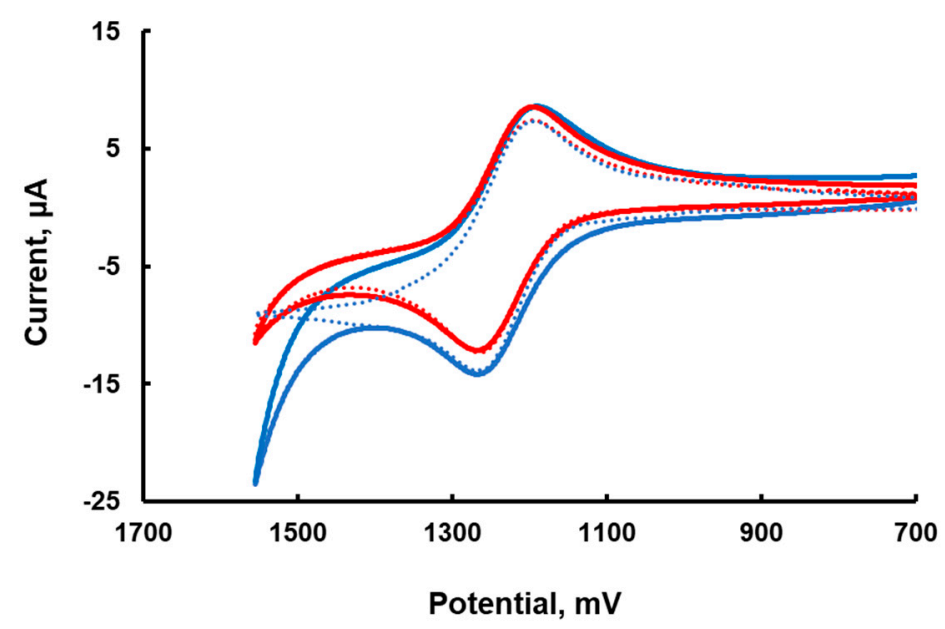

Figure 1. Cyclic voltammograms of $1.0 \mathrm{mM}\left[\mathrm{Ru}(\mathrm{bpy})_{3}\right] \mathrm{Cl}_{2}$ in $80 \mathrm{mM}$ sodium phosphate at $\mathrm{pH} 7.2$ (red) and in the presence of $15 \mu \mathrm{M} \mathrm{R \mathbf {u } _ { 4 }} \mathbf{P O M}$ (blue); the simulated curves are dotted lines. Scan rate, $100 \mathrm{mV} / \mathrm{s}$; potential versus SHE.

\subsection{Linear Sweep Voltammetry}

Linear sweep voltammetry (LSV) at very low scan rate with vigorous stirring of the solution is commonly used to obtain the dependence of the potential as a function of the logarithm of the current (Tafel equation). The experimental LSV curves are shown in Figure $2 \mathrm{a}$. We then plotted the applied potential (in the range $900-1200 \mathrm{mV}$ ) as a function of the current normalized per concentration of added [ $\mathbf{R} \mathbf{u}_{\mathbf{4}} \mathbf{P O M}$ ] (an analog of TOF) in Figure 2b.

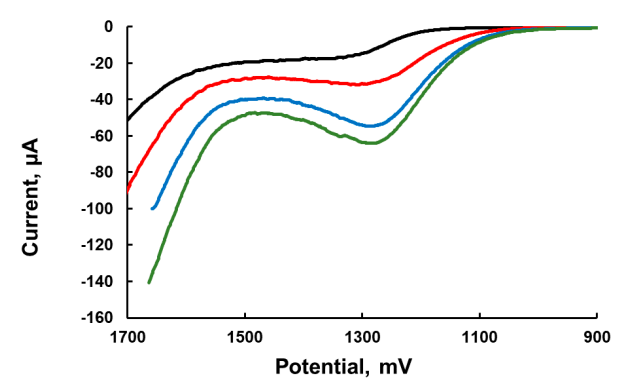

(a)

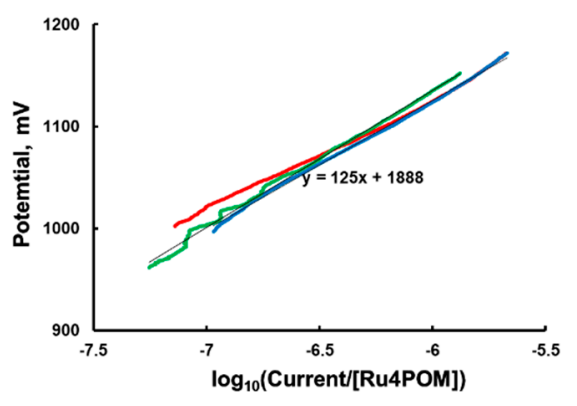

(b)

Figure 2. (a) Linear sweep voltammograms with stirring at a scan rate $3.0 \mathrm{mV} / \mathrm{s}$ of $1.0 \mathrm{mM}$ [Ru(bpy) $\left.)_{3}\right] \mathrm{Cl}_{2}$ in $80 \mathrm{mM}$ sodium phosphate at $\mathrm{pH}$ 7.2. [R $\mathbf{R}_{4} \mathbf{P O M}$ ]: 0 (black), 5 (red), 10 (blue), and $15 \mu \mathrm{M}$ (green and orange); (b) Tafel plot in the range of potentials between 900 and $1200 \mathrm{mV}$.

The "Tafel slope" in the range of potentials between 900 and $1200 \mathrm{mV}$ is $120 \mathrm{mV} /$ decade (Figure 2) for three different $\mathbf{R} \mathbf{u}_{4}$ POM concentrations. Based on the formal interpretation of the Tafel equation, this slope is consistent with $\alpha=0.5$ and a one-electron process. However, 
as the theory of such measurements is not yet developed for a homogeneous WOC system, the meaning of this slope value is unclear.

\subsection{Tafel Plot from Kinetic Curves in Homogeneous Systems}

The kinetics of water oxidation by Ru3 can be followed either by measuring oxygen formation or by the consumption/formation of Ru3/Ru2. The consumption of Ru3 can be followed by a decrease in absorbance at 670-680 $\mathrm{nm}\left(\varepsilon=420 \mathrm{M}^{-1} \mathrm{~cm}^{-1}\right)$ [14]. The reaction is fast and requires a stopped-flow instrument to collect high-quality kinetics data. The experimental details were described in our previous publications [14,19]. Both Ru2 and $\mathbf{R} \mathbf{u}_{4}$ POM slightly absorb light at $680 \mathrm{~nm}$, which must and can be taken into account for quantitative analysis of raw experimental data. Here for simplicity, a kinetic curve of [Ru3] consumption versus time is the decrease in absorbance at $680 \mathrm{~nm}$. At a given time $t$, the reaction rate can be approximated as $\mathrm{d}[\mathrm{Ru} 3] / \mathrm{dt} \approx\left([\mathrm{Ru} 3]_{(\mathrm{t}-\Delta \mathrm{t})}-[\mathrm{Ru} 3]_{\mathrm{t}+\Delta \mathrm{t})}\right) / 2 \Delta \mathrm{t}$ and $\mathrm{TOF}_{\mathrm{ap}}=(\mathrm{d}[\mathrm{Ru} 3] / \mathrm{dt}) /[\mathrm{Ct}]$ can be quantified $\left([\mathrm{Ct}]\right.$ is the total concentration of $\left.\mathbf{R} \mathbf{u}_{\mathbf{4}} \mathbf{P O M}\right)$. We make the reasonable assumption, based on our earlier studies, that the reaction mechanism is Equations (5)-(9). If reversible reactions are in equilibrium and [Ct] $<<$ [Ru3], then the electrochemical solution potential at time $t$ can be calculated from the Nernst equation $\mathrm{E}=\mathrm{E}_{0}^{\prime}+0.059 \times \log _{10}\left(\left([\mathrm{Ru} 3]_{\mathrm{t}} /\left([\mathrm{Ru} 3]_{0}-[\mathrm{Ru} 3]_{\mathrm{t}}\right)\right)\right.$, where $\mathrm{E}_{0}^{\prime}=1.26 \mathrm{~V}$ is the standard reduction potential of the $[\mathrm{Ru} 3] /[\mathrm{Ru} 2]$ couple, and [Ru3 $]_{0}$ is the initial concentration of Ru3. As Ru3/Ru2 and $\mathbf{R} \mathbf{u}_{4} \mathbf{P O M}$ have large and opposite charges, their reduction potentials and the rates of their intermolecular reactions are ionic-strength-dependent. In order to keep $\mathrm{pH}$ constant, the use of buffered solutions is required. However, even low concentrations of sodium phosphate buffer (e.g., $25 \mathrm{mM}$ ) create a high ionic strength ( $\mu \sim 75 \mathrm{mM})$. Therefore, in this work, we use the experimentally determined value of the reduction potential for the $\mathrm{Ru} 2 / \mathrm{Ru} 3$ couple as the reference point in all calculations (e.g., $1.06 \mathrm{~V}$ versus $3.0 \mathrm{M}$ $\mathrm{NaCl} \mathrm{Ag/} \mathrm{AgCl}$ reference electrode). We define TOF as $(\mathrm{d}[\mathrm{Ru} 3] / \mathrm{dt}) /[\mathrm{Ct}]$. This procedure converts a single kinetic curve to the dependence of TOF on applied potentials.

The self-decomposition of $\mathrm{Ru} 3$ is relatively slow at $\mathrm{pH} 7.0-8.0$, and the $\mathrm{O}_{2}$ yield approaches $80 \%$ of the theoretical value at $\left[\mathbf{R} \mathbf{u}_{4} \mathbf{P O M}\right]>5 \mu \mathrm{M}$. Therefore, the kinetics of $\left[\mathrm{Ru}(\mathrm{bpy})_{3}\right]^{3+}$ consumption can be considered as the kinetics of water oxidation. The beginning of kinetic curves (up to 15\% conversion) has the highest Ru3/Ru2 ratio, which quickly changes with time and makes the rate measurements problematic.

The typical kinetic curves and the corresponding Tafel-like plots are shown on Figure 3. The initial rates are commonly used to study the reaction kinetics. In this work, we did not use this approach, due to two major problems. First, if Ru2 is not added in the reaction mixture, the rate quickly changes at very low conversions, creating uncertainty in the definition of the initial rate. Secondly, in the early stage, small experimental uncertainties in $\mathrm{Ru} 2$ concentration will lead to significant errors in [Ru3]/[Ru2] ratio.

The experimental $\log _{10}$ (TOF) dependence on the electrochemical solution potential is weakly dependent on catalyst concentration and is not linear. In order to interpret the data, we build a kinetic model of homogeneous processes, performed the fitting of kinetics curves, and then simulated the Tafel plot. It appeared that the simulated Tafel plots are weakly dependent on parameters obtained from fitting. Therefore, we had to narrow the ranges of variable parameters using additional sets of experimental data. In this respect, differential pulse voltammetry could be helpful to estimate the oxidation potentials of $\mathrm{Ru}_{4}$ POM. 


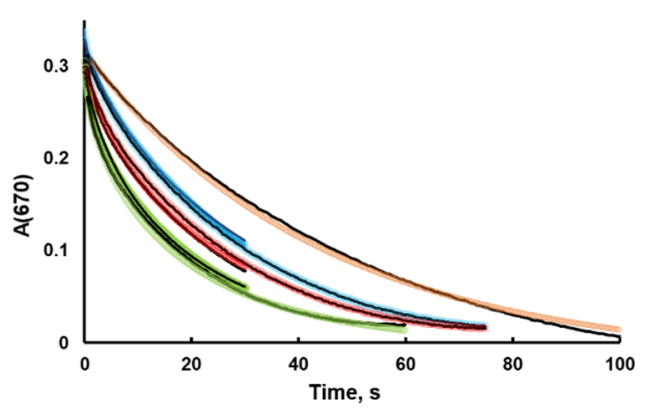

(a)

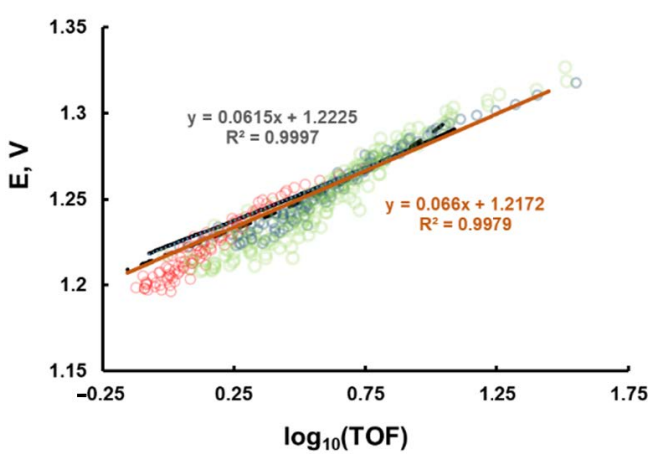

(b)

Figure 3. (a) The kinetics of $\left[\mathrm{Ru}(\mathrm{bpy})_{3}\right]^{3+}$ consumption measured at $670 \mathrm{~nm}$. Sodium borate buffer $(25 \mathrm{mM})$ at $\mathrm{pH} 8.0$, $0.85 \mathrm{mM}\left[\mathrm{Ru}(\mathrm{bpy})_{3}\right]^{3+}, \mathbf{R} \mathbf{u}_{4} \mathbf{P O M}-0$ (orange), 2.5 (blue), 5.0 (red), and $10 \mu \mathrm{M}$ (green). The fitting using Copasi software to the mechanism in Equations (15)-(21) is in solid lines [20]; (b) turnover frequency (TOF) and potential are calculated as described in the text. The brown line is calculated using Equation (15). The black line is generated by Copasi software with the same parameters as in (a).

\subsection{Differential Pulse Voltammetry}

Differential pulse voltammetry (DPV) has two features: The effect of the charging current can be minimized and only faradaic current is extracted. This technique is well suited for electrochemical examination of $\mathbf{R} \mathbf{u}_{4} \mathbf{P O M}$, which has a low rate constant of electron transfer to electrode; however, like other electroanalytic techniques, DPV requires the use of a high electrolyte concentrations. Indeed, the DPV peaks significantly increase with an increase in $\mathrm{NaNO}_{3}$ electrolyte concentration in $80 \mathrm{mM}$ sodium borate buffer at $\mathrm{pH} 8.0$ and also shift to lower potentials (Figure 4). The first peak becomes visible at $0.5 \mathrm{M}$ $\mathrm{NaNO}_{3}$ at $\sim 0.65 \mathrm{~V}$ and shifts to a lower potential at $0.75 \mathrm{M} \mathrm{NaNO}_{3}$. The width of the peak is around $90 \mathrm{mV}$, which is consistent with the one-electron transfer process (theoretical value $90 \mathrm{mV}$ ). The second peak has a width of about $45 \mathrm{mV}$ and thus is very likely a two-electron process. At low ionic strength, the potential of the second peak is in the range of 1.0-1.1 V vs. $\mathrm{Ag} / \mathrm{AgCl}$.

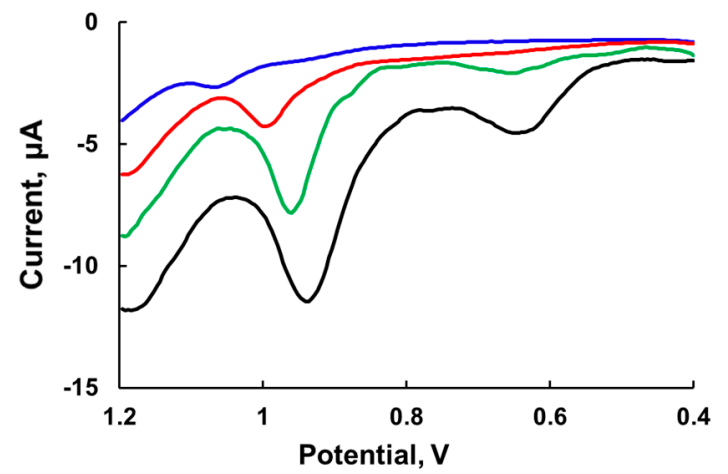

Figure 4. Differential pulse voltammetry curves of $1.0 \mathrm{mM} \mathrm{R \mathbf {u } _ { 4 }} \mathbf{P O M}$ in $80 \mathrm{mM}$ sodium borate buffer at $\mathrm{pH} 8.0$ at varying concentrations of $\mathrm{NaNO}_{3}: 0.15 \mathrm{M}$ (blue), $0.25 \mathrm{M}$ (red), $0.5 \mathrm{M}$ (green), and $0.75 \mathrm{M}$ (black). Differential pulse voltammetry (DPV) parameters: $\mathrm{V}(\mathrm{mV} / \mathrm{s})=20$, sample width $(\mathrm{ms})=17$, pulse amplitude $(\mathrm{mV})=50$, pulse width $(\mathrm{ms})=50$, pulse period $(\mathrm{ms})=200$, quiet time $(\mathrm{s})=2$.

We considered studying the kinetics of water oxidation at elevated concentrations of electrolyte in order to have the similar conditions to those used in electrochemical studies. However, the rate of water oxidation by Ru3 decreases with an increase in electrolyte concentration due to ionic strength effects, but the rate of Ru3 self-decomposition remains unchanged and becomes the predominant kinetic event. As such, the redox potentials 
measured by DPV could be extrapolated to low ionic strength to estimate the possible range of $\mathbf{R u _ { 4 }} \mathbf{P O M}$ potentials.

\subsection{Kinetic Model of Homogeneous Water Oxidation by $\left[R u(b p y)_{3}\right]^{3+}$ Catalyzed by $\mathbf{R} \mathbf{u}_{4} \mathbf{P O M}$}

Having information on the range of redox potentials of $\mathbf{R u}_{4} \mathbf{P O M}$ and making minimal assumptions, the mechanism in Equations (16)-(22) is proposed:

$$
\begin{array}{r}
\mathrm{C} 0+\mathrm{Ru} 3 \rightleftarrows \mathrm{C} 1+\mathrm{Ru} 2 \mathrm{k}_{1}=1 \times 10^{10} ; \mathrm{k}_{-1}=10 \mathrm{M}^{-1} \mathrm{~s}^{-1} ; \mathrm{K}_{1}=1 \times 10^{9} ; \Delta \mathrm{E}_{1}=-0.61 \mathrm{~V} \\
\mathrm{C} 1+\mathrm{Ru} 3 \rightleftarrows \mathrm{C} 2+\mathrm{Ru} 2 \mathrm{k}_{2}=1 \times 10^{10} ; \mathrm{k}_{-2}=(4.6 \pm 8) \times 10^{5} \mathrm{M}^{-1} \mathrm{~s}^{-1} ; \mathrm{K}_{2}=2.2 \times 10^{4} ; \Delta \mathrm{E}_{2}=-0.26 \mathrm{~V} \\
\mathrm{C} 2+\mathrm{Ru} 3 \rightleftarrows \mathrm{C} 3+\mathrm{Ru} 2 \mathrm{k}_{3}=1 \times 10^{10} ; \mathrm{k}_{-3}=(5.4 \pm 9) \times 10^{5} \mathrm{M}^{-1} \mathrm{~s}^{-1} ; \mathrm{K}_{3}=1.8 \times 10^{4} ; \Delta \mathrm{E}_{3}=-0.26 \mathrm{~V} \\
\mathrm{C} 3+\mathrm{Ru} 3 \rightleftarrows \mathrm{C} 4+\mathrm{Ru} 2 \mathrm{k}_{4}=(1.5 \pm 0.8) \times 10^{7} ; \mathrm{k}_{-4}=(8.0 \pm 4) \times 10^{8} \mathrm{M}^{-1} \mathrm{~s}^{-1} ; \mathrm{K}_{4}=0.2 ; \Delta \mathrm{E}_{4}=0.10 \mathrm{~V} \\
\mathrm{C} 4 \rightarrow \mathrm{C} 0+\mathrm{O}_{2} \quad \mathrm{k}_{0}=18 \pm 2 \mathrm{~s}^{-1} \\
\mathrm{Ru} 3 \rightarrow \mathrm{Ru}_{\mathrm{x}} \quad \mathrm{k}_{\mathrm{d}}=0.0023 \pm 0.0005 \mathrm{~s}^{-1} \\
10 \mathrm{Ru} 3+\mathrm{Ru}_{\mathrm{x}} \rightarrow 10 \mathrm{Ru} 2+\operatorname{Pr} \mathrm{k}_{\mathrm{dd}}>1 \times 10^{5} \mathrm{M}^{-1} \mathrm{~s}^{-1}
\end{array}
$$

The latter two reactions are added to describe the rate and stoichiometry of the Ru3 self-decomposition reaction in the absence of a catalyst. The values were determined from the fitting of five kinetic curves and assuming the rate law for Equation (21) as $\mathrm{d}[\mathrm{Ru} 3] / \mathrm{dt}=-\mathrm{k}_{\mathrm{dd}}[\mathrm{Ru} 3]\left[\mathrm{Ru}_{\mathrm{x}}\right]$. It appeared that the overall reaction rate and $\mathrm{O}_{2}$ yield are independent of $k_{d d}$, if $k_{d d}>1 \times 10^{5} \mathrm{M}^{-1} \mathrm{~s}^{-1}$. We assumed that the very thermodynamically favorable reactions between two reactants with opposite charges proceed with the diffusioncontrolled rate constants $1 \times 10^{10} \mathrm{M}^{-1} \mathrm{~s}^{-1}$. The optical density at $670 \mathrm{~nm}$ was calculated as $\mathrm{A}(670)=420 \times[\mathrm{Ru} 3]+20 \times[\mathrm{Ru} 2])$. The results of the fitting are strongly dependent on dioxygen yield over the reaction time. Therefore, we used an additional set of experimental data. The dioxygen yield at $20 \pm 2 \mathrm{~s}$ was measured to be 41,60 , and $85 \mu \mathrm{M}$ in the presence of 2.5, 5.0, and $10 \mu \mathrm{M} \mathrm{Ru} \mathbf{u}_{4} \mathbf{P O M}$, respectively. The calculated values of $\mathrm{O}_{2}$ were the same as the experimental ones within a $5 \%$ range. For each concentration of $\mathbf{R u}_{4} \mathbf{P O M}$, two kinetic curves with different reaction times were used. The results of the fitting are given in Figure 3 and the values of the parameters are given in Equations (16)-(22). The values of the variable parameters are highlighted in italics. The standard deviations are generated by the fitting software. As expected, the values of rate constants extracted by fitting have a large error range due to the low number of experimental curves used in fitting. The increase in the numbers of curves requires much longer computing time and results in only a slight decrease in accuracy of the extracted parameters. As the focus of this work is not the study of the explicit reaction mechanism, we did not fit a large set of experimental curves.

It is important to note that the Tafel-like plot cannot be used to confirm a specific kinetic model. However, it can provide additional information about the activity of a catalytic system.

\subsection{Comparison of Different Homogeneous Catalytic Systems Using Tafel-Like Plots}

First, we used the kinetic data on $\mathrm{O}_{2}$ evolution in water oxidation by $\mathrm{Ce}$ (IV) under acidic conditions catalyzed by $\mathbf{R} \mathbf{u}_{4} \mathbf{P O M}$ [15]. The experiment was performed in unbuffered $1.1 \mathrm{mM} \mathrm{Ce}(\mathrm{IV})$ solution. The estimated $\mathrm{pH}$ was 2.5. The standard redox potential of the $\mathrm{Ce}(\mathrm{IV}) / \mathrm{Ce}(\mathrm{III})$ couple was taken to be $1.5 \mathrm{~V}$ [21-23]. The value of the overpotential was calculated as a difference between the Nernstian electrochemical solution potential $(\mathrm{E}=1.5+0.059 \times \log ([\mathrm{Ce}(\mathrm{IV})] /[\mathrm{Ce}(\mathrm{III})]))$ and the standard oxidation potential of water $(\mathrm{E}=1.24-0.059 \times \mathrm{pH})$. We digitized the data in Figure S10 from Ref. [15] and obtained the Tafel plot in Figure 5 (blue circles). Based on our kinetic model, we simulated the dependence of TOF for $\mathrm{O}_{2}$ formation as a function of overpotential at $\mathrm{pH} 8.0$ (Figure 5 red circles). As expected, both sets of data form almost a straight line with a slope of $67 \mathrm{mV}$ per decade, which describes the catalytic activity of $\mathbf{R u}_{4} \mathbf{P O M}$ over a wide range of conditions. 


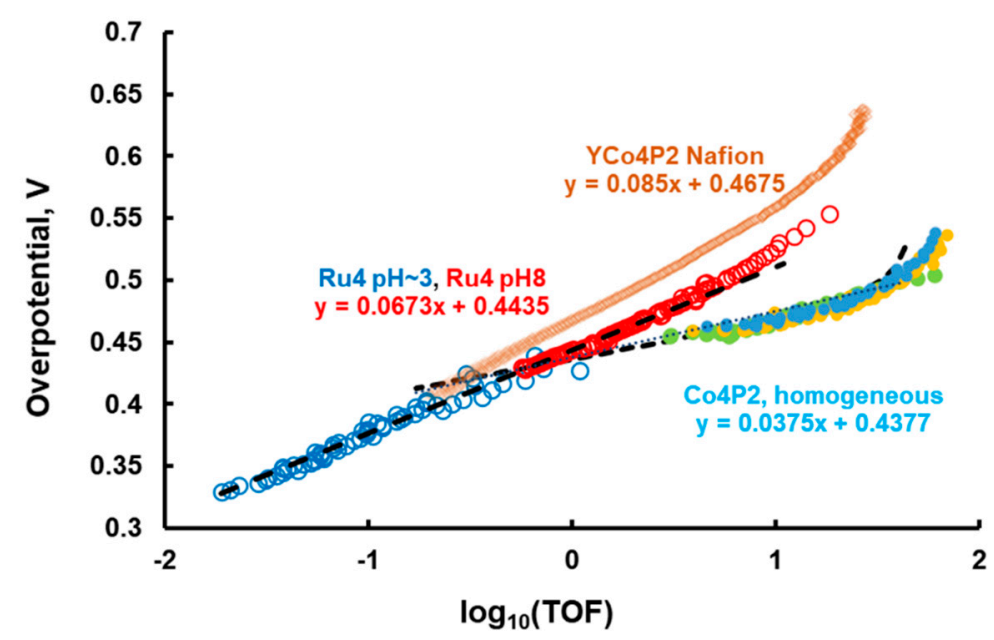

Figure 5. Tafel-like plots for water oxidation catalyzed by soluble $\mathbf{R u}_{4} \mathbf{P O M}$ and Co4POM (completely homogeneous catalysts) derived using the described methodology compared to heterogenized POM Tafel plots measured via electrochemistry. Conditions for $\mathbf{C o}_{4} \mathbf{P O M}$ system: $80 \mathrm{mM}$ sodium borate buffer at pH 8.0, 0.34 mM Ru3, 2.5 (light blue), 5 (green), 10 (yellow) $\mu \mathrm{M} \mathrm{Co} 4$ POM, $24{ }^{\circ} \mathrm{C}$.

Finally, we collected stopped-flow data for another well-established homogeneous WOC, $\left[\mathrm{Co}_{4}\left(\mathrm{H}_{2} \mathrm{O}\right)_{2}\left(\mathrm{PW}_{9} \mathrm{O}_{34}\right)_{2}\right]^{10-}\left(\mathrm{Co}_{4} \mathbf{P O M}\right)$ [24], in $80 \mathrm{mM}$ sodium borate buffer at $\mathrm{pH}$ 8.0 under conditions similar to those for $\mathrm{Ru}_{4} \mathbf{P O M}$. The data were processed in the same way as described above, where the TOF for $\mathrm{O}_{2}$ formation is equal to $1 / 4$ of the TOF for Ru3 consumption, and plotted in Figure 6. The $\mathbf{C o}_{4} \mathbf{P O M}$ is more active than $\mathbf{R u}_{4} \mathbf{P O M}$ at overpotentials lower than $0.44 \mathrm{~V}$, while it is lower at overpotentials higher than $0.44 \mathrm{~V}$. The differences in Tafel slopes indicate that the rate-determining steps and/or the corresponding WOC reaction mechanism are different in these two systems.

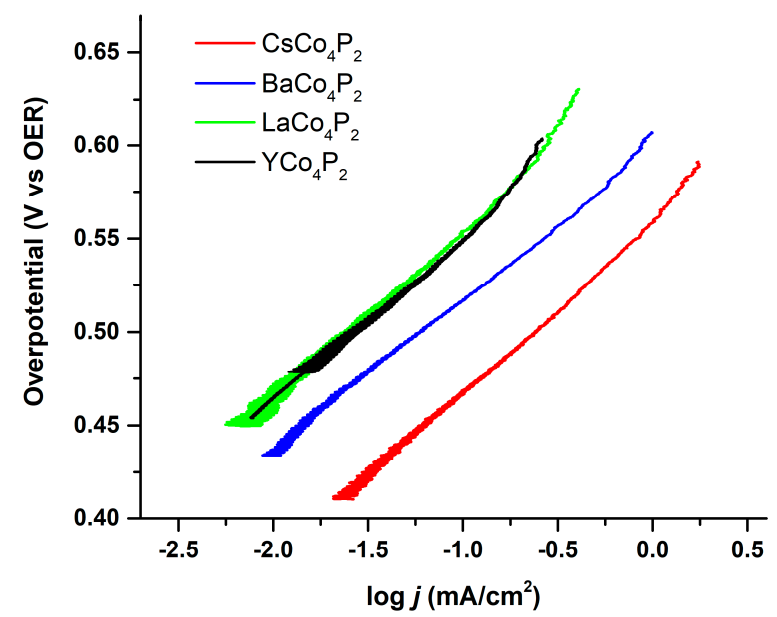

Figure 6. Tafel plot of heterogenized $\mathrm{Co}_{4} \mathrm{POM}$ on glassy carbon electrodes with different counterions. Conditions: $1 \mathrm{mV} / \mathrm{s}$ iR compensated chronoamperometry in $0.1 \mathrm{M} \mathrm{pH} 8$ sodium borate buffer and $0.1 \mathrm{M} \mathrm{KNO}_{3}$ electrolyte solution. Reference electrode, $\mathrm{Ag} / \mathrm{AgCl}(1.0 \mathrm{M} \mathrm{KCl})$; counter electrode, graphite.

In order to understand how the reaction parameters in Equations (15)-(21) affect the Tafel slope, we simulated the Tafel slope using Copasi and then observed the effects of changing each of the parameters within a range of $10^{4}-10^{6}$ from the fitted values of $\mathbf{R u}_{4} \mathbf{P O M}$. We have found that if the equilibrium of the reaction in Equation (19) is shifted to the left side (corresponding to the condition that the first oxidation potential is very high), then the Tafel slope becomes $30 \mathrm{mV} /$ decade. This leads us to believe that the first 
oxidation potential of $\mathrm{Co}_{4} \mathbf{P O M}$ is higher and the step depicted in Equation (19) becomes rate-determining instead.

Here, it is worth mentioning that experimental slopes in Figure 3 are slightly higher than the theoretical 30 and $60 \mathrm{mV} /$ decade. The TOF was also calculated based on the rate of Ru3 consumption, which includes the Ru3 self-decomposition side reaction that we deemed negligible for our analysis.

\subsection{Tafel Slope for Heterogeneous $\mathrm{Co}_{4} \mathbf{P O M}$ Complex}

One of the reasons for performing a Tafel-like analysis on the homogeneous catalysts is to make comparisons to the analogous heterogeneous catalysts where accessible. Various different counter-cation variants of $\mathrm{Co}_{4} \mathrm{POM}$ were heterogenized via a $5 \mathrm{wt} \%$ Nafion mixture and drop-casted onto a glassy carbon electrode in order to measure their Tafel behavior. These Tafel plots are shown in Figure 6. They all exhibit similar Tafel slopes of about $80 \mathrm{mV} /$ decade, which is greater than the $60 \mathrm{mV} /$ decade observed for amorphous cobalt oxides. This suggests either a different WOC mechanism or different cobalt-centered active species are involved in with the two types of cobalt-containing WOCs. Nonetheless, it is likely that all these variants of $\mathbf{C o}_{4} \mathbf{P O M}$ have the same rate-determining step given their similar Tafel slopes.

As the current in these electrochemical experiments can be directly converted to TOF (four electrons per turnover), we can then compare the Tafel plots of the heterogenized $\mathrm{Co}_{4} \mathrm{POM}$ to those of the homogeneous $\mathrm{Co}_{4} \mathbf{P O M}$ (Figure 5). We note that these samples have similar electroactive surface areas as measured by capacitive current. The differences in exchange current density must therefore be a result of counterion effects. In this case, as they follow the expected trend of lower Lewis acidity, giving rise to higher catalytic currents, we can generally attribute the observed trend to their Lewis acid-base chemistry.

\section{Materials and Methods}

All common synthetic chemicals were reagent grade and purchased through commercial sources such as Sigma-Aldrich and VWR and used without further purification. Synthesis of $\mathbf{R u}_{4} \mathbf{P O M}$ and $\mathbf{C o}_{4} \mathbf{P O M}$ was performed following exact literature procedures and recrystallized from aqueous solution $[14,24]$. Synthesis of the $\left[\mathrm{Ru}(\mathrm{bpy})_{3}\right]^{3+}$ source, $\left[\mathrm{Ru}(\text { bpy })_{3}\right]\left(\mathrm{ClO}_{4}\right)_{3}$, was obtained by oxidizing $\left[\mathrm{Ru}(\text { bpy })_{3}\right] \mathrm{Cl}_{2}$ using $\mathrm{PbO}_{2}$ in $0.5 \mathrm{M} \mathrm{H}_{2} \mathrm{SO}_{4}$ and precipitating by addition of $\mathrm{HClO}_{4}$ [25]. The product was then dried and stored in a refrigerator $\left(4^{\circ} \mathrm{C}\right)$.

Stopped-flow UV-Vis spectroscopy was performed on a Hi-Tech KinetAsyst Stopped Flow SF-61SX2 instrument equipped with a diode array detector operating between wavelengths ranging from 400 to $700 \mathrm{~nm}$. One of the feeding syringes was filled with a solution of $\left[\mathrm{Ru}(\mathrm{bpy})_{3}\right]^{3+}$ and the second with a freshly prepared buffer solution containing the catalyst. The consumption of $\left[\mathrm{Ru}(\mathrm{bpy})_{3}\right]^{3+}$ was followed by a decrease in absorbance at $670 \mathrm{~nm}\left(\varepsilon_{670}=4.2 \times 10^{2} \mathrm{M}^{-1} \mathrm{~cm}^{-1}\right)$ with an optical path length of $10 \mathrm{~mm}$. The data were acquired and treated using KinetAsyst ${ }^{\mathrm{TM}} 3.0$ software. Consequent analysis of the resulting kinetic data were performed using Excel and the Copasi software package [20].

Electrochemical analyses were carried out using standard three-electrode measurements on a Pine Research Instrument WaveDriver 20 bipotentiostat and a BAS CV-50W potentiostat. All potentials were measured using glassy carbon electrodes against $1 \mathrm{M} \mathrm{KCl}$ $\mathrm{Ag} / \mathrm{AgCl}$ reference electrodes $(+0.235 \mathrm{~V}$ vs. NHE) purchased from $\mathrm{CH}$ Instruments. The counter electrodes were either a platinum wire or a graphite rod. Electrochemical cells were either cylindrical or conical electrochemical glassware or three-necked round-bottom flasks. All electrochemical measurements were done with the reference and working electrodes in proximity and clear from obstructions that would hinder contact with the reaction solution.

\section{Conclusions}

We describe a protocol to obtain Tafel-like plots for two different homogeneous catalytic systems based on kinetic and thermodynamic data. These plots visualize the 
activity of different catalysts under different solution overpotential conditions and allow for the ready comparison of their activity with each other, as well as with heterogeneous catalysts whose Tafel plots can be obtained using a traditional electrochemical setup. The resulting Tafel slopes indicate that the reaction mechanisms in water oxidation catalyzed by $\mathbf{R} \mathbf{u}_{4} \mathbf{P O M}$ and $\mathbf{C o}_{4} \mathbf{P O M}$ are likely different with distinct rate-determining steps.

This establishes a template with which molecularly discrete homogeneous WOCs can be directly compared to each other, regardless of the oxidant used, and addresses one of the biggest issues in WOC development: that of how to compare the catalytic reactivity of homogeneous and heterogeneous systems. In the future, we hope to expand upon this work and show further utilization of these protocols to elucidate the reaction mechanisms of other WOC systems.

Author Contributions: Conceptualization, Q.Y. and Y.V.G.; methodology, Y.V.G.; formal analysis, Q.Y. and Y.V.G.; investigation, Q.Y., Z.X. and Y.V.G.; writing-original draft preparation, Q.Y. and Y.V.G.; writing-review and editing, T.L., D.G.M. and C.L.H.; visualization, Q.Y. and Y.V.G.; funding acquisition, T.L., D.G.M. and C.L.H. All authors have read and agreed to the published version of the manuscript.

Funding: This research was funded by the U.S. Department of Energy, Office of Science, Office of Basic Energy Sciences, Solar Photochemistry Program, Award Number DE-FG02-07ER15906.

Data Availability Statement: Data is contained within the article.

Conflicts of Interest: The authors declare no conflict of interest. The funders had no role in the design of the study; in the collection, analyses, or interpretation of data; in the writing of the manuscript, or in the decision to publish the results.

\section{References}

1. Bard, A.J.; Faulkner, L.R. Electrochemical Methods: Fundamentals and Applications, 2nd ed.; John Wiley \& Sons: Hoboken, NJ, USA, 2000.

2. Shinagawa, T.; Garcia-Esparza, A.T.; Takanabe, K. Insight on Tafel slopes from a microkinetic analysis of aqueous electrocatalysis for energy conversion. Sci. Rep. 2015, 5, 13801. [CrossRef] [PubMed]

3. Hu, J.-M.; Zhang, J.-Q.; Cao, C.-N. Oxygen evolution reaction on IrO2-based DSA ${ }^{\circledR}$ type electrodes: Kinetics analysis of Tafel lines and EIS. Int. J. Hydrogen Energy 2004, 29, 791-797. [CrossRef]

4. Anantharaj, S.; Ede, S.R.; Karthick, K.; Sam Sankar, S.; Sangeetha, K.; Karthik, P.E.; Kundu, S. Precision and correctness in the evaluation of electrocatalytic water splitting: Revisiting activity parameters with a critical assessment. Energy Environ. Sci. 2018, 11, 744-771. [CrossRef]

5. de Chialvo, M.R.G.; Chialvo, A.C. Hydrogen evolution reaction: Analysis of the Volmer-Heyrovsky-Tafel mechanism with a generalized adsorption model. J. Electroanal. Chem. 1994, 372, 209-223. [CrossRef]

6. Walter, M.G.; Warren, E.L.; McKone, J.R.; Boettcher, S.W.; Mi, Q.; Santori, E.A.; Lewis, N.S. Solar Water Splitting Cells. Chem. Rev. 2010, 110, 6446-6473. [CrossRef] [PubMed]

7. Li, D.; Lin, C.; Batchelor-McAuley, C.; Chen, L.; Compton, R.G. Tafel analysis in practice. J. Electroanal. Chem. 2018, 826, 117-124. [CrossRef]

8. Marshall, A.T.; Vaisson-Béthune, L. Avoid the quasi-equilibrium assumption when evaluating the electrocatalytic oxygen evolution reaction mechanism by Tafel slope analysis. Electrochem. Commun. 2015, 61, 23-26. [CrossRef]

9. Savéant, J.-M. Molecular Catalysis of Electrochemical Reactions. Mechanistic Aspects. Chem. Rev. 2008, 108, 2348-2378. [CrossRef]

10. Lauinger, S.M.; Yin, Q.; Geletii, Y.V.; Hill, C.L. Chapter Five-Polyoxometalate Multielectron Catalysts in Solar Fuel Production. In Advances in Inorganic Chemistry; van Eldik, R., Cronin, L., Eds.; Academic Press: Cambridge, MA, USA, 2017; Volume 69, pp. 117-154.

11. Sumliner, J.M.; Lv, H.; Fielden, J.; Geletii, Y.V.; Hill, C.L. Polyoxometalate Multi-Electron-Transfer Catalytic Systems for Water Splitting. Eur. J. Inorg. Chem. 2014, 2014, 635-644. [CrossRef]

12. Roger, I.; Shipman, M.A.; Symes, M.D. Earth-abundant catalysts for electrochemical and photoelectrochemical water splitting. Nat. Rev. Chem. 2017, 1, 0003. [CrossRef]

13. Costentin, C.; Savéant, J.-M. Homogeneous Molecular Catalysis of Electrochemical Reactions: Catalyst Benchmarking and Optimization Strategies. J. Am. Chem. Soc. 2017, 139, 8245-8250. [CrossRef] [PubMed]

14. Geletii, Y.V.; Besson, C.; Hou, Y.; Yin, Q.; Musaev, D.G.; Quiñonero, D.; Cao, R.; Hardcastle, K.I.; Proust, A.; Kögerler, P.; et al. Structural, Physicochemical, and Reactivity Properties of an All-Inorganic, Highly Active Tetraruthenium Homogeneous Catalyst for Water Oxidation. J. Am. Chem. Soc. 2009, 131, 17360-17370. [CrossRef] [PubMed] 
15. Sartorel, A.; Carraro, M.; Scorrano, G.; Zorzi, R.D.; Geremia, S.; McDaniel, N.D.; Bernhard, S.; Bonchio, M. Polyoxometalate Embedding of a Tetraruthenium(IV)-oxo-core by Template-Directed Metalation of $\left[\gamma-\mathrm{SiW}_{10} \mathrm{O}_{36}\right]^{8-}$ : A Totally Inorganic OxygenEvolving Catalyst. J. Am. Chem. Soc. 2008, 130, 5006-5007. [CrossRef] [PubMed]

16. Lee, C.-Y.; Guo, S.-X.; Murphy, A.F.; McCormac, T.; Zhang, J.; Bond, A.M.; Zhu, G.; Hill, C.L.; Geletii, Y.V. Detailed Electrochemical Studies of the Tetraruthenium Polyoxometalate Water Oxidation Catalyst in Acidic Media: Identification of an Extended Oxidation Series using Fourier Transformed Alternating Current Voltammetry. Inorg. Chem. 2012, 51, 11521-11532. [CrossRef] [PubMed]

17. Costentin, C.; Drouet, S.; Robert, M.; Savéant, J.-M. Turnover Numbers, Turnover Frequencies, and Overpotential in Molecular Catalysis of Electrochemical Reactions. Cyclic Voltammetry and Preparative-Scale Electrolysis. J. Am. Chem. Soc. 2012, 134, 11235-11242. [CrossRef] [PubMed]

18. Martin, C.R.; Rubinstein, I.; Bard, A.J. The heterogeneous rate constant for the Ru(bpy)33+/2+ couple at a glassy carbon electrode in aqueous solution. J. Electroanal. Chem. Interfacial Electrochem. 1983, 151, 267-271. [CrossRef]

19. Vickers, J.W.; Sumliner, J.M.; Lv, H.; Morris, M.; Geletii, Y.V.; Hill, C.L. Collecting meaningful early-time kinetic data in homogeneous catalytic water oxidation with a sacrificial oxidant. Phys. Chem. Chem. Phys. 2014, 16, 11942-11949. [CrossRef]

20. Hoops, S.; Sahle, S.; Gauges, R.; Lee, C.; Pahle, J.; Simus, N.; Singhal, M.; Xu, L.; Mendes, P.; Kummer, U. COPASI-A COmplex PAthway SImulator. Bioinformatics 2006, 22, 3067-3074. [CrossRef]

21. Bilal, B.A.; Müller, E. Thermodynamic Study of Ce4+ /Ce3+ Redox Reaction in Aqueous Solutions at Elevated Temperatures: 1. Reduction Potential and Hydrolysis Equilibria of Ce4+ in HCIO4 Solutions. Z. Nat. A 1992, 47, 974-984. [CrossRef]

22. Bouchaud, B.; Balmain, J.; Bonnet, G.; Pedraza, F. pH-distribution of cerium species in aqueous systems. J. Rare Earths 2012, 30, 559-562. [CrossRef]

23. Hayes, S.A.; Yu, P.; O’Keefe, T.J.; O'Keefe, M.J.; Stoffer, J.O. The Phase Stability of Cerium Species in Aqueous Systems. J. Electrochem. Soc. 2002, 149, C623. [CrossRef]

24. Yin, Q.; Tan, J.M.; Besson, C.; Geletii, Y.V.; Musaev, D.G.; Kuznetsov, A.E.; Luo, Z.; Hardcastle, K.I.; Hill, C.L. A Fast Soluble Carbon-Free Molecular Water Oxidation Catalyst Based on Abundant Metals. Science 2010, 328, 342-345. [CrossRef] [PubMed]

25. Shafirovich, V.Y.; Khannanov, N.K.; Strelets, V.V. Chemical and Light-Induced Catalytic Water Oxidation. New J. Chem. 1980, 4 , 81-84. 